PERTENECE A:

UNIVERSIDAD CENTROAMERICANA J. S.

BIBLIDTEEA

"P. FLORENTINO IDOATE, S. J."

\title{
La Cumbre de la tierra en su entorno mundial
}

\author{
Francisco Javier Ibisate
}

\section{Resumen}

La cumbre de la tierra es un examen de conciencia sobre el funcionamiento de la actual globalización porque, con el deterioro ecológico, se integra un abanico de problemas, agravados por la actual mundialización, donde la interrogante mayor es el éxito y los fracasos del libre mercado y del comercio internacional. Las anunciadas ventajas no se desparraman sobre las tres cuartas partes de la humanidad. Por supuesto, esto es lo que vivimos en nuestra realidad nacional, porque no somos unos extraterrestres. Escuchamos "la voz de la naturaleza", porque no utiliza palabras huecas.

\section{Introducción}

Las organizaciones no gubernamentales participantes en la cumbre de Johannesburgo protestan por los escasos resultados: "es un crimen y una traición para cientos de millones de personas pobres". El Secretario General de Naciones Unidas, Kofi Annan, ha quedado satisfecho con los compromisos logrados: "un impulso que hay que apoyar". Algunos jefes de Estado o de gobierno, que no asistieron a la cumbre, juzgan que hay problemas más importantes y urgentes, en el mundo de hoy. Tal vez, la fecha en la cual tuvo lugar esta cumbre, del 26 de agosto al 4 de septiembre, no ha sido la más afortunada al coincidir con las celebraciones preparalorias del primer aniversario del 11 de septiembre, en la "ciudad mártir" de Nueva York.

En el mes de mayo, el presidente G. W. Bush visitó cuatro capitales europeas -Berlín, Moscú, París y Roma- para persuadir a sus gobiernos de que el problema número uno del mundo es la lucha contra el terrorismo, la nueva amenaza global. El viaje se cerró con la Declaración de Roma y la creación del Consejo OTAN - "Vivimos un mundo nuevo, donde nuevas amenazas y desafíos exigen respuestas cada vez más unidas. Por esta razón, los estados miembros de la OTAN y la Fede- 
ración de Rusia abrimos un nuevo capítulo en nues২. tras relaciones". De los hechos a los hechos. Dos días después de clausurarse la cumbre de Johannesburgo, Estados Unidos e Inglaterra "lanzan el mayor ataque contra las defensas iraquíes en cua- tro años" (El País, 6 de septiembre de 2002). Pero Bush no logró convencer a París, Moscú y Pekín de que ésla us la mejor alternativa para construir un mundo más pacílico (Le Monde, 6 de sepliembre de 2002).

En este entorno mundial, va a ser muy difícil querer convencernos, los unos a los otros, sobre cuál sea el problema número uno del mundo, cuando el hecho real es que se suman y retroalimentan los problemas de largo plazo, recogidos en la Declaración de Johanesburgo, y los derivados de los odiosos sucesos del 11 de septiembre y del 7 de ^octubre. En la cumbre de Davos, en Nueva York (febrero de 2002), se habló de "economía frágil, de incertidumbre y de inseguridad": "la globalización de la ira se ha acelerado con el rápido crecimiento de las desigualdades sociales" (ECA, 2002, p. 62). Para expresarlo en otras palabras, dos recientes publicaciones presentan la sumatoria de eslos problemas. En La crisis del 11 de septiembre: ¿qué cambiará? (Madrid, 2002), un grupo de catedráticos universitarios expone, en forma sencilla, los cambios y los efeclos que se avecinan en el mediano plazo. En el mes de mayo ya se habia agolado, en España, la traducción del libro escrito por el Premio Nobel de Economía 2001, Joseph Stiglitz, El malestar en la globalización (Madrid, 2002). "Una guía para todos sobre el mal gobierno de la globalización”, Kennet Galbraith.

También va a ser difícil que lleguemos a un acuerdo, los unos y los otros, sobre el éxito o el fracaso de la presente Cumbre de la tierra, centrada en el desarrollo sostenible, entre una y otra generación. Es difícil calibrar los resultados cuantitativos y cualitativos de estas cumbres mundiales, donde, por lo menos, se va creando conciencia de que "otro mundo es posible". Cuántas veces nos han defraudado los magros resultados de anteriores foros y reuniones mundiales, donde los discursos y las palabras huccas contrastan con los escasos compromisos reales. Pero incluso estos magros resultados han logrado un efecto positivo: la creciente secuencia de protestas que buscan traducirse en propuestas. $x$ Stiglitz dice que "Las protestas han provocado un enorme caudal de exámenes de conciencia desde el poder político. Incluso los políticos conservado- res, como el presidente francés, Jacques Chirac, han manifestado preocupación porque la globaliza. ción no está mejorando la vida de quienes más *necesitan de sus prometidas ventajas. Es claro para todo el mundo que algo ha funcionado terriblemente mal. Prácticamente, de la noche a la mañana, la globalización se ha vuelto el asunto más apremiante de nuestro liempo, que se discule en las salas de juntas y en páginas editoriales y en escuelas de todo el planeta" (p. 28).

La cumbre de la tierra es un examen de conciencia sobre el funcionamiento de la actual globalización porque, con el deterioro ecológico, se integra un abanico de problemas, agravados por la actual mundialización, donde la interrogante mayor es el éxito y los fracasos del libre mercado y del comercio internacional. Las anunciadas ventajas no se desparraman sobre las tres cuartas partes de la humanidad. Por supuesto, esto es lo que vivimos en nuestra realidad nacional, porque no somos unos extraterrestres. Escuchamos "la voz de la naturaleza", porque no utiliza palabras huecas.

\section{La Declaración de Johannesburgo sobre el desarrollo sostenible}

He aquí un exlracto del documento:

Hace diez años en Río [Janeiro] reconocimos que la prolección del medio ambiente y el desarrollo económico y social eran los tres pilares inseparables del desarrollo durable. Con tal fin, aprobamos la agenda 21 (Le Monde agrega que se ha suprimido una frase de la versión previa del documento, donde los signalarios "reconocían que los objelivos paclados en la cumbre de Río no se han respetado").

Reconocemos que la erradicación de la pobreza, la protección y gestión de los recursos naturales para el desarrollo económico y social son objetivos claves y exigencias esenciales para el desarrollo durable. La profunda brecha que divide la sociedad entre ricos y pobres y la fosa que se extiende entre los mundos desarrollados y en desarrollo constituyen la amenaza mayor para la prosperidad, la seguridad y la estabilidad mundiales. El medio ambiente mundial sigue deteriorándose. Se malogra la biodiversidad, se reducen los bancos de peces, la desertificación invade más y más ticrras fértiles, los efectos destructivos del cambio climático son bien evidentes, las catástrofes naturales son más frecuen- 
tes y devastadoras, y los países en desarrollo son los más vulnerables; la polución del agua

\% priva a millones de personas de condiciones de vida decente.

La mundialización agrega una nueva dimensión a estos desafíos. La rápida integración de los mercados, la movilidad de los capitales y el incremento del flujo de inversiones plantean nuevos desafios y nuevas oportunidades en la búsqueda del desarrollo durable. Pero los beneficios y los costos de la mundialización están desigual-

- mente distribuidos, quedando los países en desarrollo confrontados a mayores dificultades para enfrentar este desafío. Nos comprometemos, a través de objetivos concretos, calendarizados y con la colaboración (pública y privada) a incrementar lo antes posible el acceso a las mínimas exigencias, como el agua limpia, el saneamiento, la energía, el cuidado de la salud, la seguridad alimentaria y la protección de la biodiversidad.

Invitamos encarecidamente a los países, que aún no lo han hecho, a aportar la cantidad de ayuda para el desarrollo, pactado a escala internacional. Creemos ser necesario que las grandes empresas del sector privado den muestras de responsabilidad y transparencia. Nos comprometemos a reforzar y mejorar la realización, a todos los niveles, de los objetivos de la Declaración del Milenio y del Plan de Acción de Johannesburgo, a fin de dar cumplimiento a la Agenda 21. Reafirmamos nuestro compromiso con los principios y fines de la carta de las Naciones Unidas y del derecho internacional, así como el fortalecimiento del multilateralismo (Le Monde, 6 de septiembre de 2002).

Ignacio Ramonet, director de Le Monde Diplomatique, presenta un breve prefacio histórico de la cumbre, integrando algunos datos ecológicos. Señala siete puntos que deberían integrarse en el plan $\checkmark$ de acción de Johannesburgo. Son 191 los paises representados en la cumbre, 180 los jefes de Estado o gobierno y unos 60 mil participantes, venidos de otros 180 países. "Tres interrogantes: ¿cómo preservar el medio ambiente? ¿Cómo erradicar la pobreza?

- ¿Cómo salvar nuestro planeta? Porque la tierra está mal, muy mal. 'Salvar el planeta'. Hace diez años, en Río Janeiro, había sonado la alarma: se recalienta el clima, el agua limpia es un bien escaso, decenas de especies vivas se extinguen, la pobreza tolal abate a más de un millar de seres humanos... La causa principal de la degradación progresiva del medio

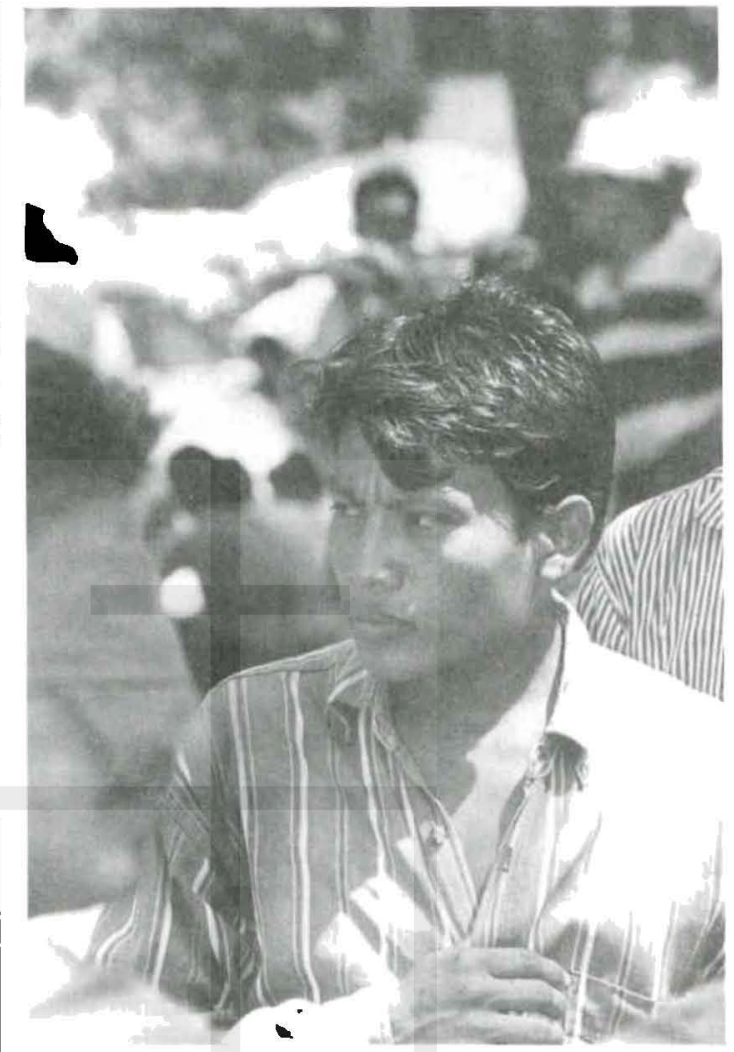

- ambiente mundial es el esquema de consumo y de producción inviable, sobre todo en los países industrializados, que es extremadamente preocupante por cuanto agrava la pobreza y los desequilibrios".

El desarrollo durable supone la aplicación de tres principios: "el principio de precaución, que busca más bien prevenir que reparar; el principio de la solidaridad entre las generaciones actuales y futuras, y entre todas las poblaciones del mundo; y el principio de participación de todos los actores sociales, en la toma de decisiones". Diez años después de Río Janeiro no se ha mejorado la situación. "Todo lo contrario. Con la aceleración de la mundialización liberal ha crecido el esquema inviable de consumo y de producción. La desigualdad ha alcanzado niveles jamás conocidos desde el tiempo de los faraones... También crece la contaminación creada por el mundo rico sobre la bioesfera. Sus emanaciones de gas, de efecto invernadero, son diez veces - mayores que las de países del sur... Más de mil millones de personas no disponen de agua potable y casi tres mil millones consumen agua contaminada. Debido a la ingestión de esta agua, 30000 
personas mueren cada día. Son diez veces más, $\times$ cada día, que el número de víctimas de los odiosos atentados del 11 septiembre...".

Prosigue la devastación de los bosques: cada año desaparecen 17 millones de hectáreas, cuatro veces la superficie de Suiza. Como los árboles no están allí para absorber los excedentes de gas carbónico, se agrava el efecto invernadero y el reca-

- lentamiento de la tierra. Cada año se extinguen 6 mil especies animales. Amenaza una extinción masiva (el 13 por ciento de los pájaros; el 25 por ciento de los mamíferos y el 34 por ciento de peces). Una extinción que no había ocurrido desde la desaparición de los dinosaurios. Esto significa que Johannesburgo despierta una gran esperanza, que puede terminar en una gran decepción "si se imponen los egoísmos nacionales, la lógica productivista, el espíritu mercantil y la ley del beneficio".

Para salvar el planeta sería indispensable que los poderes de este mundo adoplasen, al menos, siete importantes decisiones: un programa internacional a favor de las energías renovables y su acceso a los países del sur; compromisos reales para hacer faclible el acceso al agua y a su depuración, a fin de reducir a la mitad, de aqui al 2015, el número de personas privadas de este recurso vital, patrimonio común de la humanidad; políticas para proteger los bosques, tal como se determinó en la convención sobre biodiversidad, firmada en Rio (1992); resoluciones que se traduzcan en un marco jurídico sobre la responsabilidad ecológica de las empresas, reafirmando el principio de precaución, como prerrequisito de toda actividad comercial; acuerdos para subordinar las reglas de la Organización Internacional del Comercio a los principios de Naciones Unidas sobre la protección de los ecosistemas; acuerdos para exigir que los países desarrollados se comprometan a dedicar el 0.7 por ciento de su PIB a la ayuda pública para el desarrollo y, finalmente, recomendaciones serias con vistas a aliviar la deuda pública de los países pobres. Al destruir el mundo actual lo hacemos cada día menos viable. Esta cumbre debe conducir a tomar las medidas apropiadas para conseguir una ecología integral. Estc es el gran desafío del siglo XXI. De lo contrario, el género humano está amenazado de extinción" (Le Monde Diplomatique, 1 de septiembre de 2002).

\section{Paréntesis: "No somos extraterrestres"}

Estos dos breves documentos muestran la importancia de la agenda que se debatiria, a lo largo de una semana, entre tantos jefes de Estado o gobierno, directores de grandes empresas, organizaciones no gubemamentales, siempre presentes, acompañadas de manifestantes pacíficos. Los dos últimos grupos lamentaron que se los relegara a unos 20 kilómetros del centro de la convención. La distancia era una barrera que limitaba su participación. Situados a miles de kilómetros de Johannesburgo, pudiéramos creer que somos lejanos extraterrestres, ajenos a estos problemas. Muchos documentos, fruto de serias investigaciones, nos advierten lo grave de nuestro deterioro ecológico y sus consecuencias sobre el crecimiento sostenible y el desarrollo social. A modo de ejemplo y de paréntesis aplicado, traslado algunos párrafos de dos recientes documentos.

En el informe del Banco Mundial, El Salvador. Estrategia de asistencia (2 de noviembre de 2001), preparado en colaboración con el gobierno, encontramos un breve apartado "Sostenibilidad del medio ambiente, preparación para desastres y derechos de tierras". Ahí se lee que "Los efectos de los terremotos se vieron exacerbados por la vulnerabilidad ambiental de El Salvador. El deterioro de los recursos naturales está estrechamente relacionado con la pobreza rural, puesto que los pobres que se dedican a la agricultura de subsistencia tienen bajos rendimientos y productividad, y contribuyen en forma involuntaria al delerioro del medio ambiente: el 75 por ciento del territorio, en que se realiza el 70 por ciento del cultivo de los cereales básicos, está sujeto a una severa erosión del suelo. La cuenca superior del río Lempa es la cuenca hidrográfica más grande e importante desde el punto de vista comercial y de ecolurismo. Tiene una población de 305000 habitantes y una superficie de 3587 kilómetros cuadrados y es especialmente vulnerable a la erosión del suelo. La degradación afecta de forma adversa la productividad agrícola y acentúa el daño provocado por los desastres naturales. Sólo el 12 por ciento de la superficie de El Salvador tiene cubierta forestal y se conservan menos del 2 por ciento de los bosques originales. La mayor parte de sus fuentes de agua dulce está contaminada por descargas químicas e industriales. Tanto la conta- 
minación urbana como la incidencia de enfermedades gastrointestinales son altas. No existe evaluación alguna de las cuencas hidrográficas o identificación de las áreas proclives a inundaciones para evilar pérdidas catastróficas causadas por los desastres naturales" (p. 19). Es un simple botón de muestra, más ampliado en el Informe de desarrollo humano 2001. No somos extraterrestres en Johannesburgo, aunque los medios de comunicación social no le hayan dado suficiente cobertura a esta Cumbre de la tierra.

Entre las investigaciones ecológicas hechas en el país recojo algunas reflexiones del llamado "libro verde" de la Fundación Salvadoreña para el Desarrollo Económico y - Social (FUSADES) - El desafío salvadoreño: de la paz al desarrollo sostenible, mayo 1997. Se trata de un documento básico para el análisis cuantitativo y cualitativo del deterioro ecológico. En la introducción se analiza "El

Prosigue la devastación de los bosques: cada año desaparecen 17 millones de hectáreas, cuatro veces la superficie de Suiza. Como los árboles no están allí para absorber los excedentes de gas carbónico, se agrava el efecto invernadero y el recalentamiento de la tierra. Cada año se extinguen 6 mil especies animales [...] les". diversidad por la deforestación, ni las pérdidas del turismo y de los beneficios recreativos potencia-

Esta Fundación estima que esta sumatoria de pérdidas, de acuerdo a estudios en otros países, no es inferior a los 200 millones de dólares anuales, "siendo el total de pérdidas estimadas de aproximadamente 500 millones de dólares al año, o sea el 5 por ciento del PIB del país. Esta cifra es comparable con las estimaciones obtenidas para otros países que experimentan niveles similares de descuido ambiental. Para poner esta cifra en perspectiva, considérese que es igual a la tasa anual de crecimiento económico de alrededor del 5 por ciento, durante los últimos años; en otras palabras, todas las ganancias del crecimiento económico sólo lograrían compensar la pérdida por la degradación ambiental" (p. IV).

\section{Esta reflexión de} FUSADES, hecha en 1997, merece un minuto de atención. Cualquier profesor o alumno de economía habrá advertido que la revista del Banco Central de Reserva, antes de 1995, nos presentaba los datos contables del producto interno bruto, del producto nacional bruto y del "producto nacional neto", descontando la depreciación de los activos nacionales. El producto nacional neto contabiliza lo que el país puede producir "sin empobrecerse". A partir de 1995, cuando se revisan las cuentas nacionales, desaparece la "variable" del producto nacional ncto. Desde entonces, el producto y la renta son "brutos". Esto merece una consideración seria, porque, a parlir de 1997, las tasas oficiales de nuestro crecimiento económico oscilan entre el 3.5 y el 2 por ciento, una tasa netamente inferior a las pérdidas ocasionadas por el deterioro ambiental, que rondan el 5 por ciento del producto interno bruto. No estamos equivocados quienes afirmamos que desde 1997, hemos dejado de crecer para comenzar a decrecer de manera lenta. Los datos oficiales del Banco Central de Reserva y de otras instituciones, incluidos los análisis de FUSADES, siguen afirmando que estamos creciendo, pero callan los datos de éstas y otras investigaciones sobre el costo 
económico del descuido ambiental. Así, al descuido ambiental se suma un "fraude contable".

El estudio de FUSADES nos muestra, página seguida, cómo se puede dar esta concatenación de causas y efectos económicos, derivados del deterioro ecológico:

Degradación ambiental y su impacto en el crecimiento sostenible. La degradación ambiental socava de muchas formas el crecimiento sostenible. Afecta negativamente tanto a la salud como a la esperanza de vida y, en consecuencia, reduce la recuperación de la inversión de capilal humano y la tasa de crecimiento económico. Reduce la productividad de la mano de obra, de las tierras y del capital y aumenta los costos de producción. Daña la infraestructura económica y aumenta la vulnerabilidad del país ante los desastres naturales. Va en detrimento del clima de inversión de la nación y del atractivo para los inversionistas extranjeros. Puede llevar a la pérdida de participación de mercados conscientes del medio ambiente y al fracaso en la explotación de oportunidades de negocios en mercados incipientes para productos y tecnologías ambientales.

Adicionalmente, la degradación ambiental reduce la calidad de vida y desgasta el apoyo a reformas económicas continuas y a políticas orientadas hacia el crecimiento, lo que es igualmente dañino que la degradación ambiental en sí misma. Por otra parte, sin crecimiento económico no se puede lograr ni sostener una prolección ambiental. El crecimiento es necesario para aliviar la pobreza, una causa importante (así como una consecuencia) de la degradación ambiental. El crecimiento es necesario para crear empleos para los que ingresan a la fuerza de trabajo y para alejarlos de actividades destructivas del medio ambiente, así como para incentivar a las personas de los ambientes degradados y abandonar actividades y práclicas insostenibles. Finalmente, el crecimiento es necesario es vital para obtener los recursos necesarios que se invertirán en la prolección y mejoramiento del medio ambiente (p. V).

Este ha sido un simple paréntesis para mostrar que no somos ajenos a los problemas del deterioro ecológico que, nacional y mundialmente, se ha convertido en una estructura de freno para el crecimiento económico, sobre todo en el tercer mundo. Aquí y en Johannesburgo se dice que la apertura externa y el libre comercio es el mejor medio y remedio para gestar el crecimiento. Pero resulta que ni el libre comercio es un comercio libre y que el deterioro ecológico nos resta competitividad para obtener los beneficios de ese "libre comercio". De todo esto se ha hablado en Johannesburgo, donde "varias organizaciones no gubernamentales abandonan la cumbre en protesta por sus escasos resultados" (El País, 4 de septiembre de 2002). No es fácil ser optimista, pero también cuesta ser totalmente pesimista, tratando de recoger, al menos, los escasos resultados.

\section{Dos discursos presidenciales}

Los discursos, cuando son sinceros y empatan con la realidad, son parte de los escasos resultados, por cuanto generan una toma de conciencia. Citamos antes a J. Stiglitz: "Incluso los políticos conservadores, como el presidente francés, Jacques Chirac, han manifestado su preocupación porque la globalización no está mejorando la vida de quienes más necesitan de sus prometidas ventajas". Chirac dijo en Johannesburgo que "nuestra casa está ardiendo". He aquí un extracto de su discurso.

Nuestra casa está ardiendo y miramos hacia otro lado. La naturaleza, mutilada, sobreexplotada, no logra reconstruirse, y nos resistimos a aceptarlo. La humanidad sufre. Sufre por el mal desarrollo, en el norte y en el sur, y seguimos indiferentes. La tierra y la humanidad están en peligro y todos somos responsables. Ya es tiempo de abrir los ojos. En todos los continentes se encienden señales de alerta. Europa está herida por catástrofes naturales y crisis sanitarias. La economía norteamericana, devoradora de recursos naturales, parece haber entrado en una crisis de confianza sobre cómo regularla. América Latina, una vez más, ha sido sacudida por la crisis financiera y también social. En Asia, la creciente polución, la niebla oscura, amenaza envenenar todo el continente. Africa está agolada por los conflictos, el sida, la desertificación, las hambrunas. Algunos países insulares peligran desaparecer por el recalentamiento climático.

No podemos decir que no lo sabíamos. Tengamos cuidado de que el siglo XXI no se convierla, para las generaciones futuras, en un crimen de la humanidad contra la vida. Queda comprometida nuestra responsabilidad colectiva. Responsabilidad, en primer lugar, de los países desarrollados, por su historia, su poder y su 
nivel de consumo. Si toda la humanidad se comportara como las naciones del norte, harían falta dos planetas para satisfacer esas necesidades. Responsabilidad, también, de los países en desarrollo: no tiene sentido olvidar los desafíos del largo plazo, en razón de las urgencias presentes. Estos países deben admitir que no tienen otra solución que buscar un modo de producción menos contaminante.

Diez años después de Río no tenemos mucho de qué enorgullecernos. La puesta en práctica de la Agenda 21 es laboriosa. La conciencia de nuestro fracaso debe determinarnos aquí, en Johannesburgo, a pactar una alianza mundial para el desarrollo durable. Una alianza, en virtud de la cual, los países desartollados emprenden la revolución ecológica, la revolución de sus modos de producción y de consumo. Una alianza que genere un esfuerzo de la solidaridad necesaria a favor de los países pobres. Una alianza que Francia y la Unión Europea aceptan. Una alianza, en virtud de la cual, el mundo en desarrollo se encamine por la vía del buen gobierno y de su propio desarrollo (Le Monde, 6 de septiembre de 2002).

Este discurso, sin duda, tiene sus claroscuros. Europa planteará compromisos cuantitativos, en el área de las energías renovables, frente a los produclores de petróleo, pero se resisle a la lotal reducción de sus subvenciones agrícolas, de acuerdo a las reducciones graduales pactadas en la Organización Mundial del Comercio, en Qatar. Tanto o más importante es el discurso del canciller de Alemania, Gergard Schroder, por cuanto integra un abanico de problemas mundiales, planteados en esta cumbre, integrando algunas medidas concretas de acción. No resulta fácil hacer un extracto de su largo discurso.

Los parlicipantes en la cumbre del desarrollo durable tienen una gran responsabilidad: asegurar el futuro de nuestro planeta. Las devastadoras inundaciones que han asolado Europa y China han sido provocadas por terribles fuerzas naturales. Pero lambién son señales, incluso serias advertencias, que la jaturaleza hace a quienes habitamos el planeta, que debería ser un lugar de vida agradable. Estas ideas estaban presentes en la cumbre del medio ambiente de Río Janeiro, hace diez años. Entonces los estados participantes adoptaron ambiciosos objetivos: la visión de un mundo exento de guerras y conflictos, de pobreza y de destrucción de la natu- raleza parecía más fácil de realizar luego de la guerra fría y del fin del antagonismo esle-oeste.

Diez años más tarde... aparecen nuevos desafíos y riesgos generadores de graves peligros. La seguridad individual y colectiva es un bien precioso, amenazado por los conflictos regionales, la criminalidad, el terrorismo, las epidemias y el riesgo medioambiental de dimensión mundial... Los cambios climatológicos, a nivel mundial, son una realidad que afecta a muchos seres humanos; la pobreza aumenta en el mundo: más de dos mil millones, casi la mitad de la humanidad, disponen de menos de dos euros al día para vivir; mil millones y medio de hombres, mujeres y niños no saben qué es un vaso de agua limpia.

El golpe de los atentados del 11 de septiembre 2001 ha obligado a gobiernos y sociedades en todo el mundo a unirse para enfrentar la amenaza del terrorismo. Esto les ha hecho comprender también que los medios militares y policíacos no son suficientes para instaurar y salvaguardar la paz y la seguridad. Aunque no existe un vínculo directo entre la mundialización de la economía y el terrorismo intemacional, no lograremos instaurar la seguridad mundial a menos que establezcamos un plan de acción para lograr la justicia mundial... Ciertamente, la mundialización es la característica principal de nuestra economía mundial. Sin embargo, no se trata de un fenómeno natural que no podamos controlar, sino de un tejido de vínculos económicos, comerciales y de comunicación que deben gobemarse desde un plan político. Por lo tanto, debemos elaborar las reglas y las normas para que el mayor número posible de hombres y mujeres pueda gozar de los beneficios reales de la mundialización e impedir los falsos desarrollos para nosotros y las futuras generaciones. Los mercados solos no pueden lograrlo...

Oponerse radicalmente a la apertura de los mercados mundiales no ayuda a los países en desamollo, sino que les priva de la posibilidad que les ofrece para salir de su pobreza. Trade is aid. Este lema ha dado sus frutos en las políticas de desarrollo: el comercio es una ayuda y, por supuesto, hablo del comercio equitativo. Sin embargo, este principio exige una especial responsabilidad a los países ricos del mundo desarrollado. Los países industriales deben abrir realmente sus fronteras a los produclos proceden- 
tes de los países en desarrollo, aunque ello choque con privilegios nacionales, como son las subvenciones agrícolas en Estados Unidos y Europa. A largo plazo, todos nos beneficiaremos de una auténlica apertura de los mercados. Eliminar las distancias entre los pobres y los ricos en el mundo, o, por to menos reducirlas considerablemente, beneficia también a un país como Alemania, que depende, más que otros, de sus exportaciones y servicios. Deseamos desarrollar y propiciar el comercio y el intercambio con las naciones menos desarrolladas. Quedó atrás la era del proteccionismo y de las barreras comerciales.

El calentamiento de la tierra no se detiene en las fronteras de los países. Rogamos insislentemente a los estados miembros de Naciones Unidas que ratifiquen lo antes posible el protocolo de Kioto y cumplan con sus objetivos. Me dirijo, sobre todo, a Estados Unidos de América para que asuma su responsabilidad en la protección del clima y colabore igualmente en la reducción de gases de efecto invernadero. Esperamos que Estados Unidos se integre de nuevo a los acuerdos internacionales sobre la protección del clima.

Una política energética durable permite conciliar la conservación de los recursos naturales con el desarrollo económico sostenido. Sabemos que los países en desarrollo no pueden, por sí solos, echar a andar una estrategia energética tan ambiciosa. Por ello, y junto con el resto de estados europeos, defendemos la ampliación de un mecanismo central para la protección mundial del medio ambiente. Presento tres propuestas concretas para propiciar, a escala mundial, el uso de encrgías renovables. Una conferencia internacional sobre energías renovables, a ejemplo de la Conferencia Internacional de Bonn sobre el agua dulce: elaborar una estrategia internacional para el desarrollo de estas energías. Propongo que una instilución de Naciones Unidas tenga como encargo concreto ayudar sobre todo a países en desarrollo a crear un sistema de aprovisionamiento de energía limpia, dando prioridad a las energías renovables. Alemania firmará con los países en desarrollo y emergentes acuerdos estratégicos con objctivos concretos adaplados a su respectiva situación, que se realicen conjuntamente...

Nuestra estrategia se articula en cuatro principios: justicia entre generaciones, calidad de vida, cohesión de nuestra sociedad y responsabilidad internacional. La humanidad posee hoy los conocimientos, la riqueza, las posibilidades técnicas y también el sentimiento de la responsabilidad común que le incumbe para resolver los problemas de nuestra tierra. Debemos asumir esta responsabilidad; nuestros hijos nos lo reconocerán (Le Monde, 3 de septiembre de 2002).

El borrador de la Declaración de Johannesburgo, el prefacio de I. Ramonet ("Salvar el planeta") y los discursos de Chirac y Schroder muestran que al tronco del deterioro ecológico se adhieren, como fuertes lianas, una diversidad de problemas: la ratificación del protocolo de Kiolo, el agua potable, las fuentes de energías renovables, el principio de precaución, los derechos humanos y sociales, el imperio del libre mercado con sus aranceles y subvenciones, los acuerdos de Naciones Unidas y las normas de la Organización Mundial del Comercio, los objetivos de las grandes empresas, la apatía y ausencia de voluntad política de muchos estados...

Bastantes comentaristas, a comenzar por las organizaciones no gubernamentales asistentes, lamentan los escasos resultados y crece la decepción al frustrarse las expectativas que despiertan esta secuencia de reuniones mundiales. Tal vez lo positivo, en palabras de Stiglitz, es que "las protestas han provocado un enorme caudal de exámenes de conciencia". Tratando de mantener la esperanza, si comparamos la cumbre de la Organización Mundial del Comercio, de Seattle (1999) con los acuerdos tomados en Qatar (2001), algo se ha avanzado, en la modulación de las normas comerciales, aunque los avances pactados en Qatar, hasta el 2004, han frenado nuevos avances en esta Cumbre de la tierra. En la criticada reunión del G-7, en Génova, y en la cumbre de Bonn (julio de 2001) se lograron nuevas ratificaciones del protocolo de Kioto y en Johannesburgo se espera alcanzar la mayoría requerida de países desarrollados, pese al aislamiento de la "gran potencia". En verdad, fue decepcionante la reunión de Monterrey, en marzo de 2002 , centrada en "el financiamiento del desarrollo y el alivio de la pobreza", porque terminó en una declaración sin compromisos, aunque afloraron dos lecciones importantes: la corrupción de gobiernos de países en desarrollo, sumada a la corrupción de algunos países donantes y acreedores, es un fuerle obstáculo para el alivio de la pobreza. También algunos se atrevieron a afirmar que el incremento de la pobreza y de las desigualdades sociales pue- 
de alimentar el temido terrorismo (Realidad, 2002, pp. 131-150).

A Johannesburgo le ha hecho bastante sombra el aniversario del 11 de septiembre, porque la lucha contra el terrorismo global iría por delante del desarrollo sostenible mundial. Ciertamente, se ha agravado el aislacionismo y el unilateralismo de Estados Unidos, olvidando "que no puede haber seguridad global sin una agenda de justicia global" (Schroder). Como dice Moisés Naím, no se ha comprendido la lección: "La superioridad militar no protege. Estados Unidos busca la protección de su ciudadanía aumentando los gastos en rubros que el 11 de septiembre no les sirvieron para nada" ( $E l$ País, 8 de septiembre de 2002). La agenda de Johannesburgo se ha vuelto más larga y compleja que la de Río Janeiro, en 1992.

\section{El protocolo de Kioto y el debate energético}

Kofi Annan había urgido su ratificación a los estados presentes en la Cumbre del milenio, en septiembre de 2000. Desde 1992, Al Gore, candidato presidencial estadounidense, lanzó la voz de alarma, en su obra La tierra en juego, donde actualiza el Informe de Roma (1972). En la reunión del G-7, en Génova, julio de 2001, y en la cumbre de Bonn se lograron avances notables en la ratificación del protocolo: los países desarrollados se comprometieron a reducir sus emisiones de gas de efecto invernadero en un 5.5 por ciento, en promedio, en el período 2008-2012, respecto a los niveles de 1990. Se estima que los países más ricos, con un 20 por ciento de la población mundial, emiten más del 60 por ciento de los gases de efecto invernadero. ¿Quiénes son los contaminadores de nuestro planeta? Estados Unidos y Canadá con el 25 por ciento; Europa con el 21 por ciento; los países asiáticos en vías de desarrollo con el 19 por ciento; la Unión Soviética con el 12 por ciento; Centroamérica y América del Sur con el 11 por ciento; los países industrializados del Pacífico asiático con el 5 por ciento; África subsahariana con el 4 por ciento y el Oriente Medio y el norte de África con el 3 por ciento.

Aunque el presidente Clinton firmó el protocolo de Kiolo, no pudo ratificarlo por oposición del senado. El presidente Bush anunció que no aceptaba los objetivos, ni los contenidos del protocolo: el texto de Kioto "es fundamentalmente defectuoso". Sin embargo, su gobierno se sigue presentando como el gran campeón del medio ambiente. Tal vez
Bush haya reflexionado sobre estas palabras en las pasadas Navidades, cuando estalló la quiebra de la empresa energética Enron, la cual salpica a la Casa Blanca. También el vicepresidente petrolero Cheney habló a favor de "la conservación de la energía" (ECA, 2001, pp. 721-722). Estados Unidos y su presidente han sido los grandes ausentes en la cumbre, pese a contribuir con el 36.1 por ciento a la emisión de gas carbónico. Sin embargo, el resto de países desarrollados, pues de ellos depende, ha logrado salvar al prolocolo de Kioto. El Secretario de Estado, Powell, tuvo que aguantar abucheos de algunas organizaciones no gubernamentales, porque su discurso no fue muy afortunado.

El protocolo ha sido prácticamente ratificado por 90 países, que representan 37.1 por ciento de estas emisiones, entre ellos Europa (24.2 por ciento) y Japón ( 8.5 por ciento). China lo acaba de ratificar, pero, considerado país en desarrollo, no cuenta para el "techo fatídico" del 55 por ciento. Tanto Canadá (3.3 por ciento) como Rusia (17.4 por ciento) han anunciado su ratificación antes de fin del año. Schroder y Blair han pedido a todos

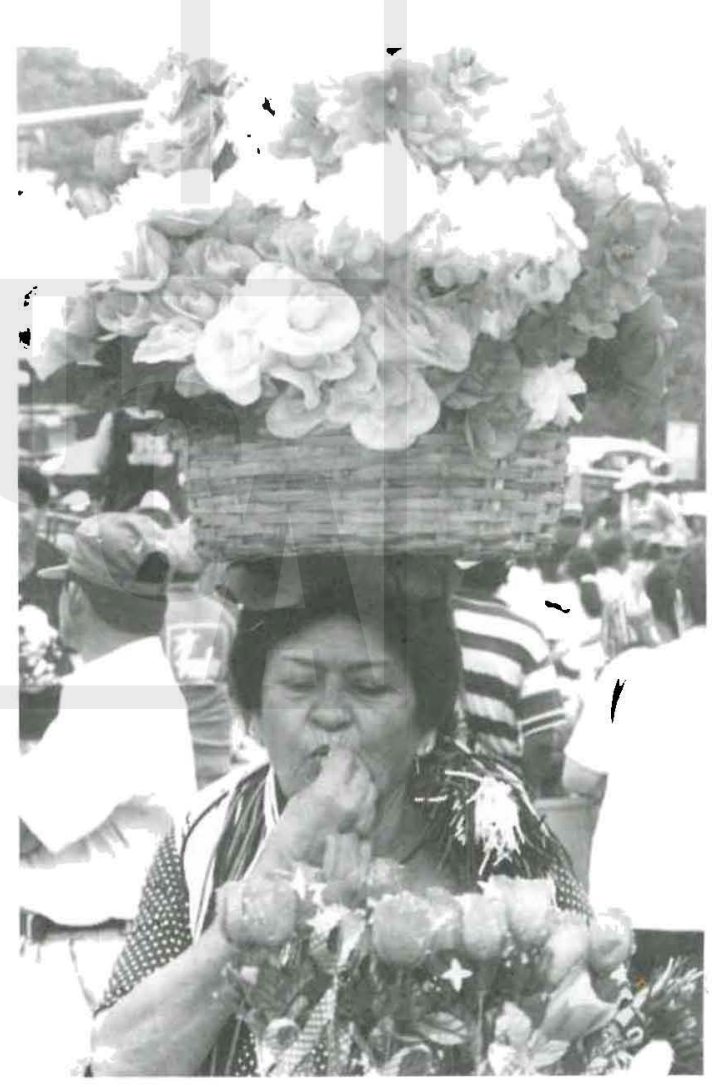


los países ratificar Kioto. El colega japonés Koizumi juzga necesario formalizar "un cuadro de acción común" contra el cambio climatológico. Prodi, presidente de la Comisión europea, predice que en el largo plazo se logrará un acercamiento entre Estados Unidos y la comunidad internacional de Kioto (Le Monde, 4 de septiembre de 2002). Sin embargo, el mismo Le Monde dice que "el encuentro de Johannesburgo confirma el aislamiento de Estados Unidos". Y El País añade, “Estados Unidos, que no parece obligado a una responsabilidad especial por su condición de máxima potencia mundial, ha puesto de manifiesto en Johannesburgo su alergia a todo tipo de atadura y compromiso multilateral, especialmente si es cifrado".

Schroder dijo que el calentamiento de la tierra no se detiene en las fronteras de los países; por ello, junto con Chirac, impulsaron el plan europeo: las energías renovables (solar y eólica) lleguen a representar el 15 por ciento del total, pero enconIraron resistencia en los países productores de petróleo, entre ellos, Estados Unidos. El plan europeo incluye aportes financieros y técnicos a los países que descen agregarse a este convenio. Dado

“Toda esta cumbre sirve para legitimar la agenda del libre comercio.

El problema es que las grandes compañías son más poderosas que los pequeños y medianos estados.

Sin dificultad podrán imponerles su propia visión. Estamos asistiendo a la ruina del medio ambiente y de lo social en nombre del desarrollo duradero". que, por influencia de Estados Unidos, no se adoptó ningún objetivo preciso sobre el aporte porcentual de las energías renovables, terminada la suscripción del plan de acción, la Unión Europea presentó oficialmente una iniciativa polílica para promoverlas. Una amplia lista de países ha suscrito la iniciativa: Bulgaria, Chipre, Chequia, los países bálticos, Hungría, Islandia, Malta, Nueva Zelanda, Noruega, Polonia, Rumania, Eslovaquia, Eslovenia, Suiza, Turquía, varios de América Lalina y, al parecer, India y Brasil. Esla larga lista significa que las energías renovables no quieren quedarse en el intero.

En un momento en que se amenaza y se cuestiona la guerra conlra Irak y se recuerda al 11 de septiembre con 30 dólares el barril de petróleo, la comunidad internacional expone la urgencia de recurrir a otras energías. "La energía contra el agua", dice un corresponsal de Le Monde, porque no se llegó a compromisos precisos sobre la energía, pero se acordó reducir, para el 2015, a la mitad el número de personas (1 100 millones) que no tienen acceso al agua potable. Se agregó el compromiso de reducir también a la mitad el número ( 2400 millones) de quienes no disponen de sistemas de saneamiento de las aguas residuales ("Cumbre sin energía", El País, 5 de septiembre de 2002; "Le Sommet de la Terre adopte un Plan d' action", Le Monde, 6 de septiembre de 2002).

\section{Las multinacionales y el desarrollo durable}

En una entrevista se cuestionó a Kofi Annan, porque las grandes empresas "piratearon" la cumbre con sus principios comerciales, mientras que las organizaciones no gubernamentales fueron marginadas, en los debates. Las primeras serian los portaestandartes del libre comercio. Kofi Annan aclaró que Naciones Unidas no podía realizar su trabajo sin estas últimas. Pero también reconoció que debe apoyarse en el sector privado, "que tiene el dincro, la capacidad de gestión y la tecnología. Las empresas son, de acuerdo a su forma de trabajo, quienes pueden aplicar lo que aquí se ha decidido. Se les pide hacer su trabajo, pero de otra forma: ellas deben sensibilizarse con el medio ambiente, el equilibrio esencial entre el desarrollo y cl medio ambiente. Lo que se busca es guiarlas y empujarlas en la buena dirección. Pido a mis amigos de las organizaciones no gubemamentales comprender y aceplar esto".

Al dirigirse a los empresarios internacionales, Kofi Annan los exhortó a comprometerse, en el largo plazo, para hacer del planeta "un lugar para una vida mejor". Los problemas sociales y del medio ambiente no pueden resolverse "sin movilizar a las empresas privadas", porque "los gobiernos no lo pueden hacer por sí solos. La situación puede mejorarse si ustedes hacen buenas opciones. En caso contrario, las jóvenes generaciones presionarán a los gobiernos para una mayor regulación de la economía". La pregunta es si las empresas están dispuestas a recoger el desafío ¿Quieren, de ver- 
dad, ayudar al desarrollo de los países emergentes? ¿Están dispuestas a aumentar sus gastos para reducir el impacto sobre el medio ambiente? Los debates han demostrado que todavía queda un largo camino por recorrer.

Las empresas tuvieron su convención cerca del centro que albergó la cumbre, mientras que las organizaciones no gubernamentales fueron colocadas a unos 20 kilómetros de distancia, lo cual generó bastantes tensiones. Las empresas se habían preparado cuidadosamente para la cumbre, porque Kofi Annan deseaba un "acuerdo global": "un acuerdo de parte de las empresas a comprometerse con el respeto de los derechos del hombre, del medio ambiente y de las leyes laborales". Pero las grandes empresas suelen obedecer a la búsqueda del beneficio. Algunos testimonios revelan que sí hubo un debate tenso.

"Nosotros, los empresarios, nos orientamos hacia la acción, mientras que las organizaciones no gubernamentales se mueven en el plano político. El desarrollo sostenido busca conciliar medio ambiente, social y económico. No veo cómo ustedes pueden lograr un desarrollo, durable o no durable, si no integran a las empresas". A lo cual Ricardo Navarro, presidente de la Internacional Amigos de la Tierra, replicó: "Por supuesto que las empresas pueden jugar un papel importante, pero ustedes están animadas por la búsqueda del beneficio. El problema es que las condiciones ambientales y sociales están sometidas a las regulaciones del comercio. El conjunto del plan de acción presenta un claro retroceso porque las decisiones de los estados en materia medioambiental deben respetar las reglas de la Organización Mundial del Comercio, situadas por encima de las nomnas intemacionales". Vino entonces, la réplica y la contrarréplica: "Puesto que el desarrollo se realizará a través del comercio y de la cooperación técnica, es normal que afloren los temas comerciales". El argumento no convence a los inconformes con la globalización: "Toda esta cumbre sirve para legitimar la agenda del libre comercio. El problema es que las grandes compañías son más poderosas que los pequeños y medianos estados. Sin dificultad podrán imponerles su propia visión. Estamos asistiendo a la ruina del medio ambiente y de lo social en nombre del desarrollo duradero".

Estos debates no han impedido que haya algunas confesiones de mea culpa por parte de los sectores empresariales, ni la firma de más de 200 acuerdos de colaboración entre empresas, organizaciones no gubernamentales e instituciones inter- nacionales o estatales ("Le Sommet de la Terre est 'piraté' par de grandes entreprises", Le Monde, 31 de agosto de 2002; "Les multinationales, acteurs et freins du développement durable", ibid., 2 de septiembre de 2002).

En este escenario se le preguntó a Kofi Annan sobre la lucha para mantener los valores de Naciones Unidas frente a los principios que defiende la Organización Mundial del Comercio. "Hemos discutido mucho este problema. Todos dicen que hay que enfatizar el compromiso de los estados miembros para tratar los problemas mundiales, subrayar la importancia de Naciones Unidas y la necesidad de su fortalecimiento. Naciones Unidas reúne a 191 páises miembros, grandes y pequeños, fuertes y débiles. Es la única institución mundial realmente representativa, donde todos participan en plan de igualdad... Los países pobres sienten que no cuentan con suficiente voz dentro de la Organización Mundial del Comercio. Naciones Unidas sirve para ayudar a los países pobres y les va a ayudar a preparar y realizar las negociaciones de la Organización Mundial del Comercio, pactadas en Qatar". Kofí Annan juzga que se ha llegado a algunos acuerdos importantes: depurar el agua, la energía, utilizar los recursos naturales y velar por su conservación. Hay que impulsar y controlar los avances paclados por los estados a partir de informes anuales. También ha habido compromisos financieros, gracias a la cumbre ("Le secretaire géneral des Nations unies, Kofi Annan, s'estime satisfait du Sommet de la Terre", Le Monde, 5 de septiembre de 2002). No entramos a comentar si algunas de las afirmaciones de Annan resultan algo benévolas y utópicas; pero hay que reconocer que la secuencia y la tenacidad en convocar tantas reuniones mundiales sirve para sacudir las conciencias de los estados grandes, de otras instituciones internacionales y ojalá que lambién de las grandes empresas.

\section{Después de Qatar sigue Qatar}

La globalización no es ni todo blanco, ni todo negro, pero después de cada cumbre mundial la vemos bastante oscura. Valga citar a dos ponderados autores. G. Schroder decía en su discurso: "Rechazar radicalmente la apertura de los mercados mundiales no ayuda a los países en desartollo, sino que les cierra la posibilidad que ella ofrece para salir de la pobreza. Trade is aid. Este lema ha dado resultados en el campo de la política de desarrollo: el comercio es ayuda y, por supuesto, hablo de un 
comercio equitativo... Los países industriales deben abrir realmente sus mercados a los productos procedentes de países en desarrollo, aunque esto parezca afectar sus privilegios nacionales, como las subvenciones agrícolas de Estados Unidos y Europa. En el largo plazo, todos nos beneficiaríamos de una verdadera apertura de mercados... La era del proteccionismo y de otras barreras ha pasado". Pero, en Johannesburgo, no se ha ratificado la profecía.

Con seguridad, Stiglitz no estará satisfecho con los resultados de la cumbre, porque ha luchado por una "globalización sin malestar". "Quienes vilipendian la globalización olvidan a menudo sus ventajas, pero los partidarios de la misma han sido incluso más sesgados; para ellos la globalización (cuando está típicamente asociada a la aceptación del capitalismo triunfante de estilo norteamericano) 'es el progreso'; los paises en desarrollo deben aceptarla si quieren crecer y luchar eficazmente contra la pobreza. Sin embargo, para muchos, en el mundo subdesarrollado, la globalización no ha cumplido con sus promesas de beneficio económico" (p. 29). Y en el prólogo de su obra dice que el malestar termina en el enfado: "La reacción contra la globalización obtiene su fuerza no sólo de los perjuicios ocasionados a los países en desarrollo por las políticas guiadas por la ideología, sino también por las desigualdades del sistema comercial. En la aclualidad - aparte de aquellos con intereses espurios que se benelician con el cierre de las puertas ante los bienes producidos por los países pobres - son pocos los que defienden la hipocresía de prelender ayudar a los países subdesarrollados, obligándolos a abrir sus mercados a los bienes de los países industrializados más adelantados y al mismo tiempo protegiendo los mercados de éstos; esto hace a los ricos cada vez más ricos y a los pobres cada vez más pobres... y cada vez más enfadados" (p.17).

El tema de las relaciones comerciales está íntimamente relacionado con el desarrollo sostenible, no sólo por sus efectos sobre la contaminación ambiental, sino también por sus efectos sobre las crecientes desigualdades económicas y sociales. Por ello se han unido ccologistas y organizaciones no gubernamentales, para que el plan de acción de la Cumbre de la tierra no quede supeditado a las leyes del libre comercio y a las normas de la Organización Mundial del Comercio. Un tema cuestionado fue el de las subvenciones que Europa y Estados Unidos vienen concediendo a la producción y exportación agrícolas. Los países del sur, agru- pados en el G-77, lo han denunciado y han solicitado una postura más crítica respecto a esta práctica.

La Unión Europea se ha resistido, ateniéndose a las conclusiones pactadas en Qatar. En esa cumbre, las subvenciones agrícolas fueron una de las “manzanas de la discordia”. Los países exportadores de produclos agrícolas reclamaban la supresión de todas las ayudas a la agricultura. El borrador inicial de Qatar decía: "reducciones de todas las formas de subvención a la exportación, con miras a su progresiva reducción". Los europeos, que defienden el "carácter multifuncional" de la agricultura, estarían dispuestos a conceder un régimen preferencial a las exportaciones de los países en desarrollo, pidiendo que reconozcan las contribuciones no comerciales (por ejemplo, las ecológicas) propias de la agricultura. En Qatar, los europeos lograron que se agregara que el término "progresiva reducción no predetermine el resultado de las negociaciones", es decir, que el resultado final será función de nuevas negociaciones, que se prolongarán en el seno de la Organización Mundial del Comercio hasta 2004 (Realidad, 2002, pp. 16 y 18). Esta es la respuesta que Europa ha ofrecido en la Cumbre de la tierra.

Las esperanzas de Qatar han sido muy pronto ensombrecidas por las medidas proteccionistas unilaterales de Estados Unidos, con sus aranceles al acero y, en especial, con las masivas subvenciones agricolas a sus granjeros, que Stiglitz calificó de hipocresía: "Es la perfecta ilustración de la hipocresía del gobiemo de Bush sobre la liberalización del comercio... Los paises del sur no tienen ninguna oportunidad de ser competitivos en esas condiciones". G. Perry, del Banco Mundial, considera que esta medida "afectará muy sensiblemente las exportaciones en América Latina. Lo que es peor aún, envía una mala señal sobre el compromiso de Estados Unidos con el libre comercio, a escala mundial y hemisférica" ("A. L. preocupada por subsidios agrícolas", La Prensa Gráfica, 7 de mayo de 2002, p. 41).

Si del nivel del gobierno pasamos al nivel de sus empresas, descubrimos nuevos ardides que algunas multinacionales nortcamcricanas utilizan para subvencionar sus exportaciones. Luego de cinco años de disputas y a solicitud de la Unión Europea, la "Organización Mundial del Comercio autoriza sanciones a Estados Unidos por 4000 millones de dólares"; "En contra de los paraísos fiscales" (La Prensa Gráfica, 31 de agosto de 2002, p. 30); "Estados Unidos tiene subvenciones ilegales: OMC" (El Dia- 
rio de Hoy, 31 de agosto de 2002, p. 35). La Organización Mundial del Comercio rechaza el sistema conocido en Estados Unidos como "Corporaciones de ventas al exterior", que permite a grandes empresas aplicar subsidios a la exportación, mediante la utilización de paraísos fiscales (las islas caribeñas), desde las cuales hacen negocios con el exterior, reduciendo hasta el 30 por ciento de la carga impositiva. De acuerdo a Le Monde, inicialmente, esta práctica beneficiaba a empresas aeronáuticas; luego, se extendió a las actividades industriales y a los servicios, apareciendo en lista empresas como Kodak, Microsoft, General Motors, Caterpillar, Chrysler, Boeing... Una gran parte de cereales y de soya sale por este canal ("L'OMC donne raison á l'Europe contre Washington", Le Monde, 31 de agosto de 2002).

Dejando de lado el hecho de que la Organización Mundial del Comercio haya pedido a Europa que estas sanciones se apliquen de forma amigable, queda bien claro que los grandes gobiemos y las grandes empresas utilizan políticas desleales e ilegales para proteger sus exportaciones. Hipocresía, comupción y fraude intelectual. En esta ocasión, ha sido la poderosa Europa la que ha ganado la batalla contra el más poderoso, Estados Unidos, mientras que a los países pobres sólo les queda armarse de paciencia o de enfado. Estos hechos debilitan la credibilidad en las virtudes del libre comercio ("democracia y desamollo" dijo Bush, en Québec) y, más específicamente, en la transparencia y equidad del ALCA. En la reunión de Madrid, en mayo de 2002, Fernando Cardoso, presidente de Brasil, dijo: "Hay una preocupación respecto a la sinceridad del compromiso de la comunidad intemacional con el libre comercio y con la construcción de un orden propicio para todos. Hay una percepción de que el proteccionismo ha sido condenado como instrumento de desarrollo de los más pobres, tan sólo para convertirse en instrumento de defensa de los privilegios de los más ricos" (El País, 18 de mayo de 2002).

Luego de este itinerario se explica la decepción de los inconformes con la globalización: "Varias organizaciones no gubernamentales abandonan la cumbre en protesta por sus escasos resultados" ( $E l$ País, 4 de septiembre de 2002). O la despiden con una marcha fúnebre (Le Monde, 4 de septiembre de 2002). Otros debates, como la inclusión de los derechos sociales en las relaciones comerciales, quedaron en vía muerta, porque pueden utilizarse como una medida de proteccionismo disimulado. Tampoco

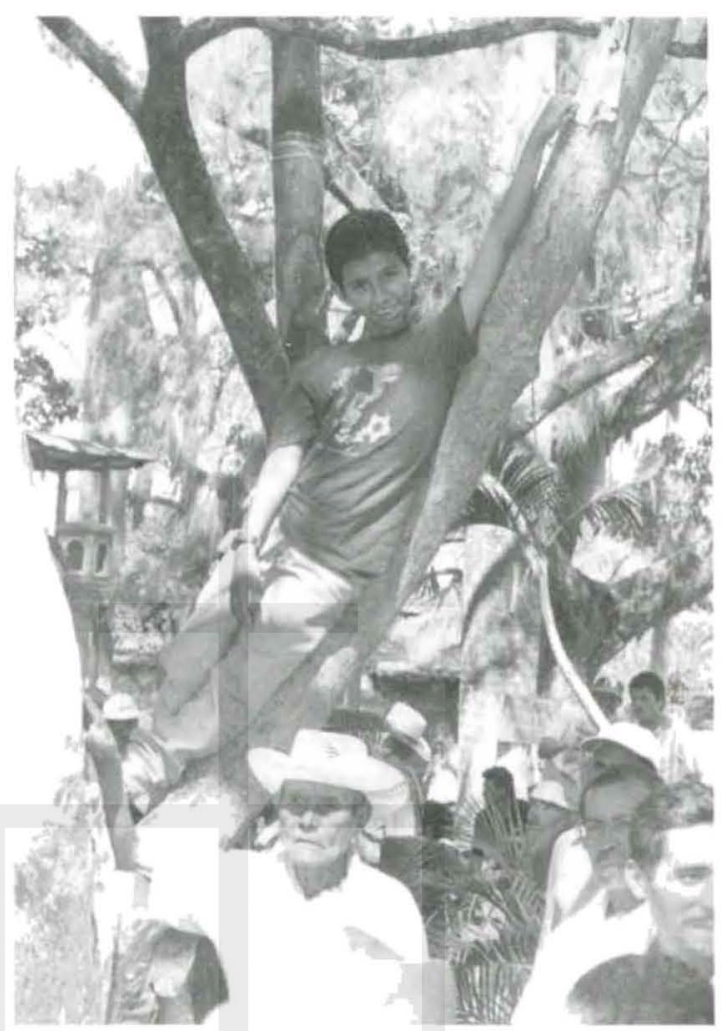

hubo espacio final para el delicado tema de los derechos sanitarios y reproductivos de la mujer, sólo se incluye una referencia a "los derechos humanos y libertades fundamentales", que equilibra la fórmula anterior. El texto de 65 páginas recoge 2500 recomendaciones, aprobadas hace diez años en Río. No todo ha sido tiempo perdido. Sin duda, serán más los convencidos de que "la tierra está mal, muy mal", y tal vez algo se haga por salvarla, porque la naturaleza no nos habla con palabras huecas. También hemos aprendido que la globalización funciona mal, muy mal, incluso en el país más rico.

\section{7. "EI terrorismo de cuello blanco"}

Hoy, 11 de sepliembre, hemos seguido de lejos las celebraciones del primer aniversario de los hechos odiosos de Nueva York. Mañana, el presidente Bush hablará en Naciones Unidas, donde presentará las pruebas de que Irak acumula armamento nuclear y bacteriológico con fines terroristas. El presidente busca la aprobación del Consejo de Seguridad para proseguir la guerra, ya iniciada o para justificar el "ir por su cuenta". Pasado mañana o al 
día siguiente de pasado mañana, el gobierno de Bush tendrá que enfrentar, de cara a la nación, los problemas muy graves y costosos que está generando en Estados Unidos "el terrorismo de cuello blanco". En la reunión de Davos, en Nueva York, el arzobispo de Canterbury, G. Carei, dijo: "El capitalismo plantea hoy un gran interrogante. Es una palabra y es Enron" (ECA, 2002, p. 69).

Norman Birnbaum, catedrático emérito de Georgetown, amplía la información: "La economía está en recesión, la renta estancada, el paro en alza. Las pruebas de delitos de fraude, con un coste devastador para empleados y accionistas, proliferan en las esferas más altas del capitalismo estadounidense. La carrera del presidente y el vicepresidente como empresarios da pie para que se les formulen una serie de reproches, o incluso abre el camino para un procesamiento. La mitad de la nación ha sufrido pérdidas en sus cuentas de acciones de interés variable y duda de su capacidad para pagar la universidad de sus hijos o para jubilarse decentemente. La desconfianza y el pesimismo han sustiluido al optimismo de los noventa" ("EE.UU.: una oposición sin convicción", El País, 31 de agosto de 2002).

Moises Naím, director de la revista Foreing Policy, comenta seis sorpresas, al cumplirse el primer aniversario del 11 septiembre: "La crisis económica: Ken Lay hizo más daño que Bin Laden. Quizá la principal sorpresa de los ataques terroristas fuera lo resistente que resultó la economía estadounidense a ese golpe en su corazón financiero. No hubo una corrida bancaria, la bolsa de valores no colapsó ni operacional, ni financieramente, ni hubo fuga de capitales, no aparecieron impedimentos permanentes al comercio intemacional, ni al tránsito de personas. Tampoco se produjo una recesión mundial. Fue sorprendente que nada de esto ocurriera. Pero una sorpresa aún mayor fue que Enron, Wordlcom o Arthur Andersen fueran más nefastos para la economia estadounidense que Al Qaeda. Un estudio reciente estimó que las quiebras de Enron y Worldcom lendrán un impacto negativo en la economía de Estados Unidos, equivalente al que tendría un aumento de 10 dólares en el precio del barril de petróleo" (El País, 8 de septiembre de 2002).

Joaquín Estefanía inicia su artículo, "Las torres gemelas del capitalismo", con esta cita: "Krugman ha escrito que el escándalo de la empresa Enron (contabilidad creativa para engañar a los ciudadanos en general, a los inversores y a sus trabajadores y jubilados) marcará un punto de inflexión ma- yor para la percepción que Estados Unidos tiene de sí misma que los atentados del 11 de septiembre de 2001. Seguramente, es una hipérbole, pero sirve para analizar el papel que la economía ha jugado en este principio de siglo en el centro del sistema y, por extensión, en el resto del planeta. A partir de esa fecha, un sentimiento de pesimismo y de perplejidad se extiende por el mundo, y todavía no se ha despejado" (El Pais, 6 de septiembre de 2002).

De ninguna manera se trata de equiparar la magnitud del dolor de tantos holocaustos, presentes y pasados, que destruyen vidas inocentes, en aras de una ideología insana, con los perjuicios económicos de las quiebras y fraudes empresariales; pero sí se quiere subrayar que los fraudes empresariales, en aras de una ideología insana del lucro financiero, sacrifican la supervivencia futura de muchos seres indefensos. Aunque cualitativamente distintas, son dos formas de hacer y crear el terror y ambas reclaman que se haga justicia.

Los odiosos alaques terroristas del 11 septiembre gestaron la piedad y la compasión mundial ante la destrucción de unas tres mil vidas inocentes y generaron el miedo a que esos crueles "holocaustos" pudieran repetirse en otras ciudades del mundo. Por ello, se les ha recordado, en este primer aniversario, y se renovará el recuerdo por muchos años. También los estados y gobiernos buscan aplicar las medidas pertinenles. El interrogante es, ¿cuáles son las medidas pertinentes? Schroder dijo, en su discurso: "El golpe de los atentados del 11 de septicmbre 2001 ha obligado a gobiemos y sociedades en todo el mundo a unirse para enfrentar la amenaza del terrorismo. Esto les ha hecho comprender también que los medios militares y policíacos no son suficientes para instaurar y salvaguardar la paz y la seguridad".

El carácter belicista y de "tambores de guerra", que ha precedido y amenaza proseguir en el presente o próximo año, ¿no estará buscando distraer la atención de la gran amenaza interna que está generando el otro "terrorismo de cuello blanco"? Son muchas las personas que se hacen esta pregunta, porque da la impresión de que al Irak de Saddam Husseim le va tocar pagar los platos rotos del escurridizo Bin Laden y de las fraudulentas mega empresas, que le han hecho al país más daño que el misterioso saudita. El gobierno de Bush debe responder ante la nación por ambos terrorismos. Y por lo que loca al resto del mundo, una sola palabra: "El capitalismo plantea hoy un gran interrogante. Es una palabra y es Enron". 